\title{
THE MAXXI MUSEUM IN ROME: AN INTEGRATED SURVEY EXPERIENCE FOR THE RESTORATION OF CONTEMPORARY ARCHITECTURE
}

\author{
A. Versaci ${ }^{\text {a }}$ A. Cardaci ${ }^{\text {b }}$ \\ ${ }^{a}$ Faculty of Engineering and Architecture, University of Enna Kore, Cittadella Universitaria, Enna - antonella.versaci@ unikore.it \\ ${ }^{\mathrm{b}}$ School of Engineering, University of Bergamo, Viale Marconi 5, Dalmine - alessio.cardaci@ unibg.it
}

\author{
Commission VI, WG VI/4
}

KEY WORDS: Contemporary architecture, reinforced concrete, conservation, 3D laser scanning

\begin{abstract}
:
In recent years, the fate of contemporary buildings in reinforced concrete is becoming a growing concern due to the fast ageing of structures, however, often of great architectural and social interest. The procedures to put in place for their material and structural preservation require multidisciplinary expertise, but also new methodological insights as most of these edifices are the result of pioneering experiments and individual 'challenges' from the morphological and technical point of views. They strictly depend on both the recognition of their peculiarities and the ability to differentiate their intrinsic characteristics of inhomogeneity from insecurity factors and degradation phenomena. This paper focuses on the experience undertaken on the MAXXI, the National Museum of the $21^{\text {st }}$ century Arts, built by Zaha Hadid Architects in Rome to highlight the methodological process followed for the knowledge of this architectural work, in view of the establishment of the project for its conservation.
\end{abstract}

\section{INTRODUCTION}

The MAXXI - the National Museum of the $21^{\text {st }}$ century Arts, built by Zaha Hadid Architects in Rome - is an architectural icon that is representative of our time, but is, in particular, a work that is the fruit of a technical-constructive complexity, which necessitated the putting in place of specific and very articulate realization procedures.

The structure was strongly supported by the (at the time) Ministry for Cultural Heritage. Its erection would have been the answer to the already long manifested demand to create an Italian public museum to gather inside, the greatest testimonies of contemporary creativity in the fields of art and architecture. For its construction, it was then chosen a flat area located within the Flaminio district - bounded on one side by the Tiber River and on the other side by the historical via Flaminia - and occupied by army barracks and military buildings. The construction yard perhaps one of the most innovative in the world - was then entrusted to the Ministry of Infrastructure that followed it from 2003 - the laying of the first stone's year - to 2009, so achieving a difficult challenge that asked for a great financial effort and hard decision-making processes.

As already mentioned, the materialisation of the design idea required major structural and implementation difficulties to be addressed, related to the architect's expressive desire to leave exposed the 'grey matter' (the reinforced concrete): the skeleton and the body of the work. The realisation of the structural shell constructively constrained by the colours and textures of the carpentries, the use of the formworks and the metallic armours requested progressive adjustments aimed at obtaining that smooth and plastic concrete 'strips', firmly desired by the designer (fig. 1).

The burden of the building site, however, has left important traces: numerous signs increasingly visible on the surfaces such as the effects of micro-cracking phenomena generated by local stress, and many common defects, which resulted from the formwork's removal. It was an avant-garde construction site brought by the designer to high exasperation levels, both formal and structural. It necessitated the preparation of a selfcompacting, self-compressing and adequate self-curing cement mix (the 3-SC), able to achieve an external skin as plastic and free from roughness as possible; the choice of special structural work and metal reinforcements to obtain uninterrupted composite undulating surfaces; the programming of the jet mode and disarmament in the presence of intricate geometries and densely packed needles; as well as the establishment of protocols, as necessary, for reparation and compensation.

Despite all this attention, the outer membrane was subjected to a final make-up with the application of new fluorinated resins to mitigate the aesthetic and chromatic differences of the various cast concretes, to soften and seal the micro-crazing, and to protect the surfaces giving them hydro and oil-repellency characteristics. It was a solution devised both to improve the museum's appearance and to guarantee it a greater durability over time.

A few years after its inauguration, nonetheless, the building is showing signs of severe ageing. For this reason, the MAXXI Foundation and the Ministry of Cultural Heritage and Activities and Tourism, which together oversee the management of the museum, decided to proceed with a necessary and urgent extraordinary maintenance programme that, in all respects, should be considered an activity of restoration of contemporary architecture. An intervention that, would hopefully move away from assumptions of a return to the former splendour, by erasing the inevitable marks of the time; namely, a project not limited to the external image recovering, but really careful of its physical consistency (Varagnoli, 2002).

As it has already been done for the built heritage of several decades of the $20^{\text {th }}$ century, it is also necessary to develop interdisciplinary actions for the conservation of the reinforced concrete architecture of the $21^{\text {st }}$ century. Victims of a technological progress still not fully controlled these recent - and often by their nature 'fragile' goods - represent important evidence of the evolutionary process of human life.

Even with all the limitations and contradictions stemming from a different approach to their design and to the current perception compared to old buildings, it seems advantageous to apply the 

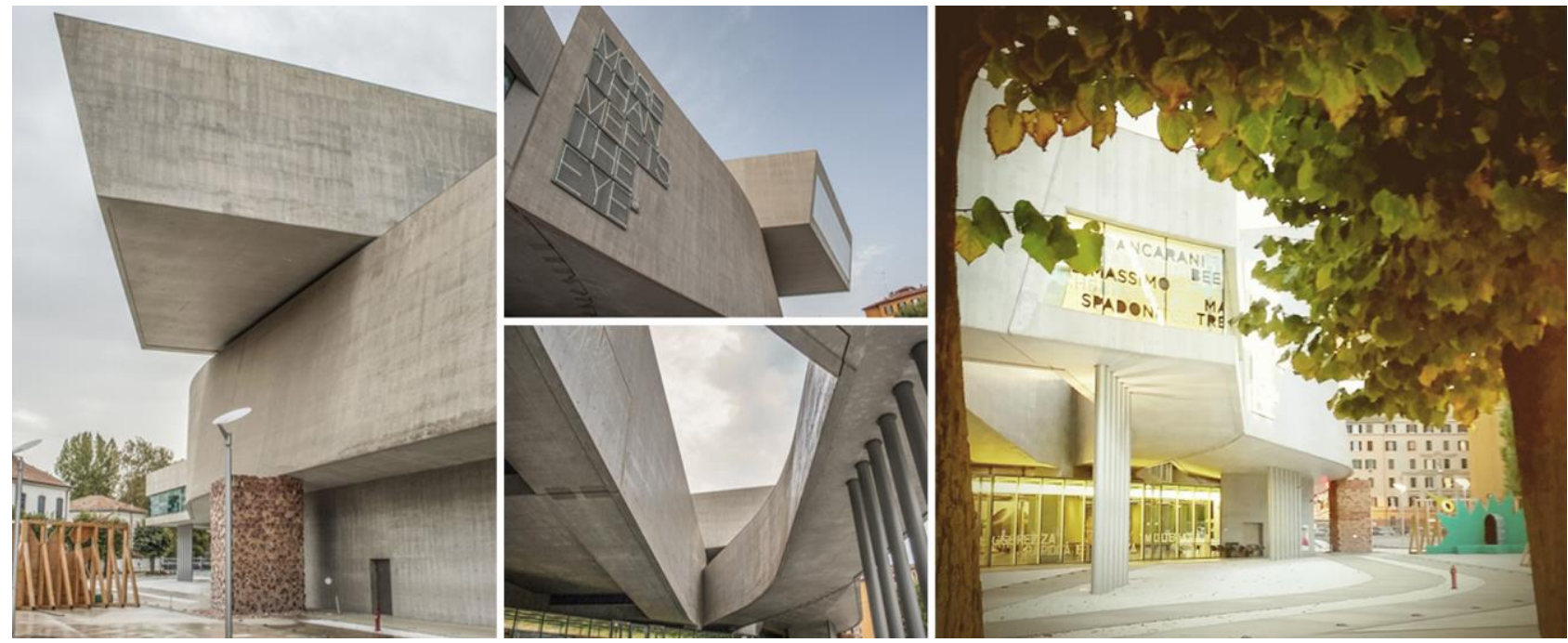

Figure 1. The MAXXI, the National Museum of the $21^{\text {st }}$ Century Arts, today

methodology already discussed and established for the preservation of historical heritage also to these works, to promote their permanence and ensure the preservation of their identities and the numerous values embodied in them.

It also appears necessary to improve a reflection on the meanings of the works and on the traces, that insist on them. Traces that are not necessarily due to an intention of the designer, but rather often the result of an inevitable sedimentation of the buildings in time and space, which as such are to be respected (Vassallo, 2004). This, within a restoration project that will not be restricted to the simple - though indispensable - understanding of the architectures, but which will become a critical, creative process, disengaged from the inopportune dispute between refurbishment and conservation that has until now dominated the restoration of modern architecture.

\section{PRELIMINARY STUDIES FOR THE CONSERVATION OF CONTEMPORARY 'GREY MATTER'}

Already interested by a phase of preliminary works that have been a place of metamorphosis, a very moment of creativity and great mediation between the matter and the form, among the structure and the architecture - essential aspects latent in the figurative program of the project - the building was involved over time in numerous repairs and improving treatments that were, unfortunately, not properly documented.

The drawings submitted by the Hadid agency represent the final design, but they not fully express the hard job of characterization, layering and improvement that was undertaken.

The above-mentioned management institutions, making use of external professional and academic consultants - among them, the authors of this paper -, have therefore initiated specific knowledge-building activities through the identification and mapping of degradation and alteration phenomena.

This task was initiated by specific metric-formal investigations and critical detection through 3D laser scanning techniques and image-based 3D modelling to both obtain virtual and solid representations useful to verify the compliance of the built architecture with the design drawings, and at the same time to generate photorealistic and orthorectified supports on which to represent the decay mapping.

Founded on the methodological and operative apparatus of the conservation discipline, the study initially required an approach to the fluid volumes that characterise the MAXXI based on 'traditional' built reading imperatives: bibliographic and archival research, collection and critical analysis of all documentation (drawings, photographs, sketches, notes), and direct observation. This analysis was integrated with a survey conducted in accordance with innovative methods and technologies, which were not though managed in an 'automatic' way, but rather were properly 'controlled' by the operators and made sensitive to the demands dictated by the purpose of the work.

It was a survey specifically conceived for the conservation project that has left no handle or bend from the machines, but which has sought to benefit from the evident advantages of technological progress to improve the understanding of the artefact - not only for measuring it - so amplifying its perception through visions and viewpoints otherwise impossible to obtain (Fiorani, 2013). This in the awareness that no amount of progress will ever allow technology to detect the very essence of a monument if the activity is not guided by the sensitivity and culture of specialists able to analyse the architecture.

The architectural survey is both an instrument devoted to the understanding of the built object in its technical and morphological components and an investigation tool able to deeply check the talent of the designer in 'creating architecture'. If according to Franco Purini, the drawing is the way the architect communicates - through graphics signs - the space that lives within its mind before the work is done (Purini, 1996), the survey allows verifying the correspondence between the project idea and the built reality.

The construction times, during which the dreams of the designer should be translated into structures and building partitions, often cause a break between the imaginary assumptions and the actual implementation, especially when the building is a multifaceted and innovative structure.

This was not the case for the MAXXI Museum. The critical analysis of the structure - conducted from iconographic material available in the archives of the Foundation - has shown the perfect correspondence between the working drawings and the as-built, so highlighting the accomplished concretization of the designer's will.

The building site has gradually given corporeality to the bold and innovative idea of Zaha Hadid. She stated in an interview how excited she was when visited it and saw how the edifice was quite emerging from the ground and how lines began to cross, as she wanted, allowing to perceive the impact that it would have in the space (RaiStoria, 2011). 
The correspondence between the survey's results and working drawings is amazing (differences are of the order of a few centimetres). It is the tangible proof of a careful and timely action in the activity carried out by the site management, as well as of a great sensitivity and designing intelligence into thinking the architectural work in its final forms.

The same attention can be found in the drawings (plans and elevations) where the holes of the formwork's connecting elements are represented by circular and/or oval shapes (obviously out of scale and emphasised), to indicate the septa's inclination.

Even working production information, often employ dimensioning rules more consistent to the mechanical than to architectural design, with an extensive use of constructive assembly drawings and clear references to strict construction protocols (Ippolito, 2016).

Surveys undertaken have caught all these aspects. Never driven by an obsession for millimetre precision, the acquisition campaigns by active sensors were conducted in a painstaking manner, performing a hundred stations to ensure the necessary accuracy but above all to fully control the activity (fig. 2).

For costs saving and a faster measuring execution time, it has been preferred not to resort to the 'classical' topographic support network, but to opt for a considerable number of acquisitions, with large overlapping areas (never less than 40\%). This enabled the obtaining of a dense points cloud - composed of over $50,000,000$ points with an average distance of $1-2 \mathrm{~cm}$ and a mean error in scans recording less than the required tolerance value for the 1:50 scale $( \pm 1.5 \mathrm{~cm})$ - and, therefore, a reliable documentation of existing condition (fig. 3 ).

The 3D laser surveying has been matched with a photographic survey, carried out in the most suitable natural lighting conditions, avoiding situations of sharp contrast, and in the hours of the day when the colour temperature could be considered reasonably constant. Each campaign was preceded by the calibration of the camera through the Xrite Colorchecker system, which, although not a strict colorimetric measuring system, has allowed a good match between the real colours and captured images (Cardaci, Versaci, 2012).

The more than fifteen hundred chromatically calibrated photographic shots were also performed in perpendicular directions to the surfaces, with an overlap between two successive snapshots of $40-60 \%$.

The processing of information resulting from acquisitions made with different techniques - a delicate praxis still subject to large experimentation - was conducted based on a surveying approach strictly targeted to the specificity of the architecture and boundary settings. It has been finalised, per a precise choice of the working team, to produce a final model combining the accuracy offered by 3D laser scanning and the high descriptive quality of 3D image-based modelling: an essential condition for the effective representation of degradation phenomena.

Such a mediation as well as the direct survey reflections have enriched the knowledge and facilitated the understanding not always 'possible' by a model produced in an automatic way. For the reconstruction of a single model, the clouds were so first filtered and pre-aligned by the creation of separate workflows (seven in total corresponding to the scanning campaigns). Subsequently, they have been joined together within a single reference system by means of a shape control algorithm.

The result provided the absolute coordinates of significant points (Ground Control Points), used in the creation of virtual models with 3D software image-based reconstruction.

The photogrammetric model was constructed from the raw images. The digital negatives - collected in homogeneous groups - have been developed in Camera Raw by adjusting, each time, the exposure, the high and low lights, the vividness and the colour saturation. It was, in fact, necessary to standardize all the shots to eliminate any differences and/or too high contrasts. The corrected images were then saved in .tiff files and imported to Structurefrom-Motion software system tools.

The procedure of 3D model construction comprised four main stages: the photographs alignment, the point cloud building (sparse and dense), the creation of polygon mesh, and then, finally, the model was textured by using the original photos. For a more successful estimation of the information on lens focal values and distortions, the camera was calibrated manually. The relative distances of the ground control points have allowed scaling, orientating, and verifying the quality of the textured model, from which hyposcopic views and orthographic projections were derived, also with a view to elaborating reliable bill of quantity estimates.
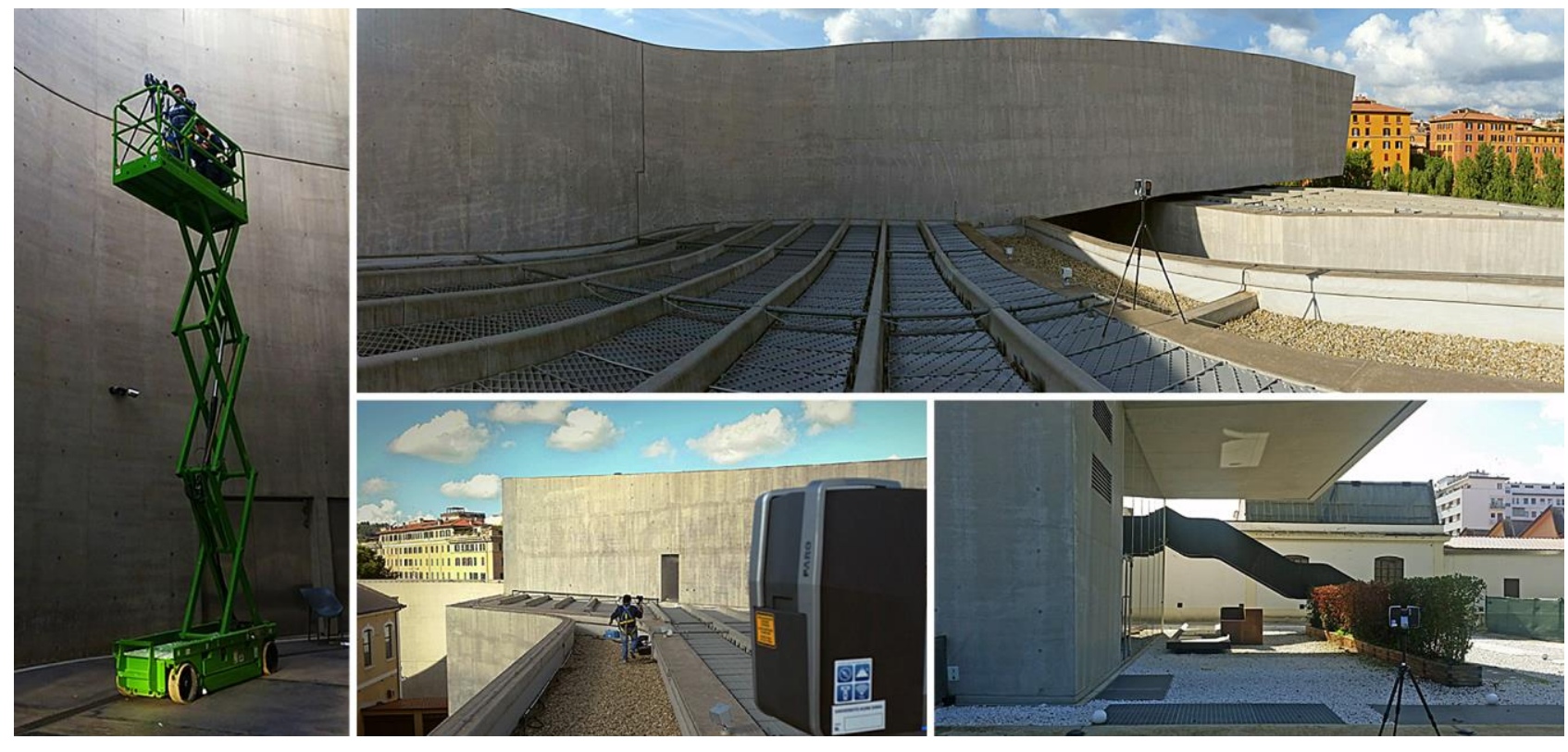

Figure 2. Architectural survey by 3D laser scanning 

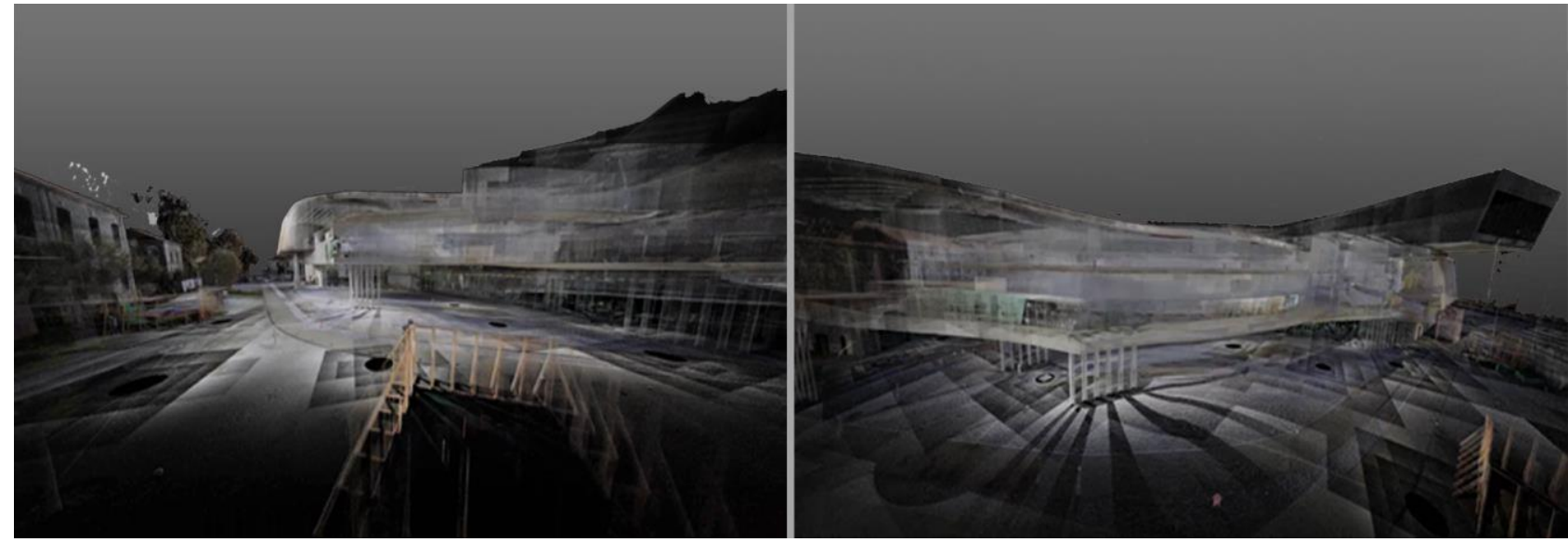

Figure 3. Point clouds obtained from the 3D laser scanning survey

\section{METHODS OF ANALYSIS AND REPRESENTATION OF CONCRETE SURFACES FOR CONSERVATION}

The activities were then aimed not only at the verification of the dimensional features, but, also and above all, at the identification of qualifying aspects of the architecture, such as the marks of deliberate construction processes. If from the metric point of view, the work is perfectly coherent with the project idea of Hadid agency, the situation is rather much more complex about its exterior 'appearance' (fig. 4). At the end of the construction work, in fact, the building was still very far from the idea of purity and perfection planned by the architect, which envisaged having impressive curved architectural structures without any defects. A radical vision maybe later mitigated, as it appears in the more recent projects (the maritime station of Salerno, the Naples
Afragola high-speed train station, etc.), where the concrete irregularities are almost seen as peculiar characteristics to be boosted. An idea perhaps approaching an older conception in vogue in the 1950s and 60s and expressed in a series of experiences ranging from Lina Bo Bardi at one extreme to Carlo Scarpa on the other, which tended to focus on the essential, praising the imperfection, in a refined use of the concrete.

For the MAXXI, numerous interventions of maquillage were needed to please the designer, by removing the peculiar defects of the matter and those due to its production. Unfortunately, these interventions were short-lived and the structure is today just as prematurely deteriorated, maybe because of a certain technological inadequacy that over time has boosted the irregularities, making them visible in an even more striking and unpleasant way (fig. 5).

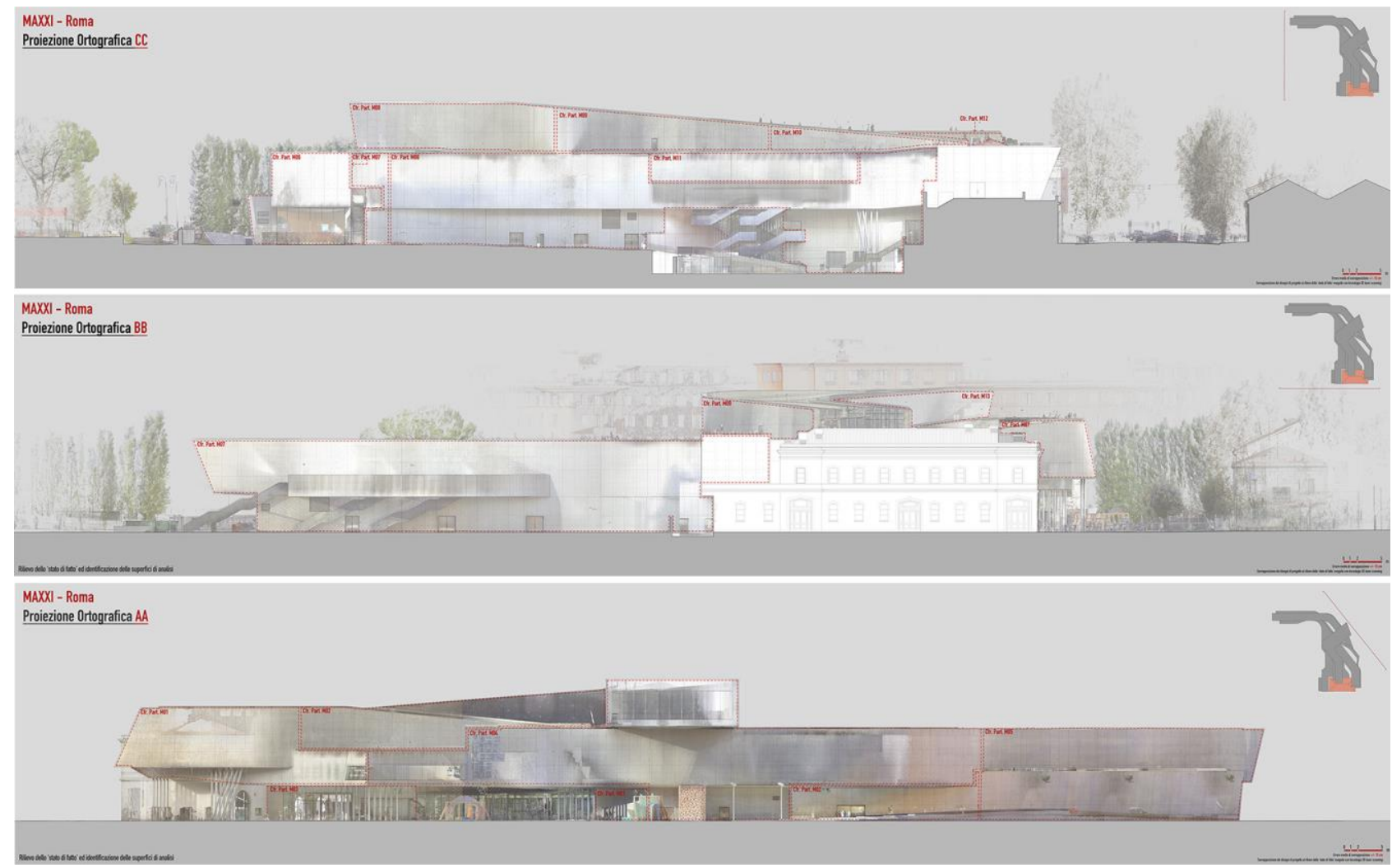

Figure 4. Orthographic projections obtained by 3D laser scanning survey 

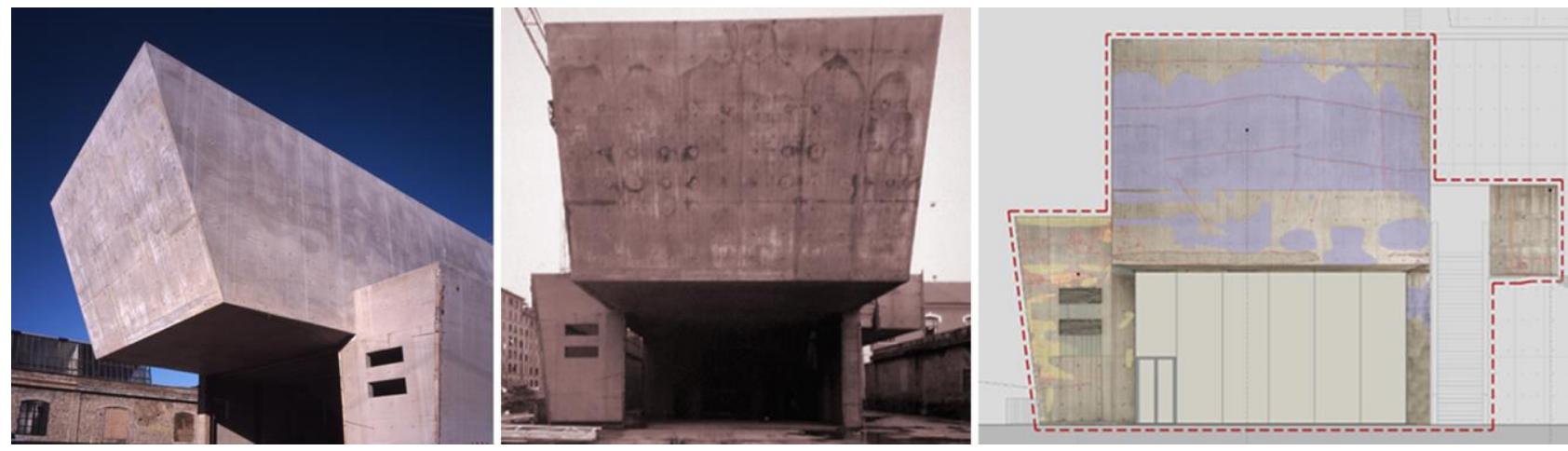

Figure 5. Detail of the west façade today (a), after the removal of the formwork (b) and decay mapping (c)

The macroscopic recognition of pathologies was then based on a visual examination suitably integrated with an explicit program of diagnostic investigations and physicochemical analysis. Especially for concrete, it appears immediately necessary to combine these insights, essential to draw definitive diagnosis, making clear in an unequivocal way, the causes of decay, often attributable to different reasons or contributing factors (Faccio, 2008).

The considered phenomena were distinguished based on their occurrence. The pathologies were divided into two categories: a first, mainly related to congenital defects (constructive and/or design errors), which also caused the emergence of minor but recurring and widespread crack patterns (i.e. mistakes in the choice of raw materials, in the conglomerate and laying production, in the concrete curing, in the removal of the formwork, in the protection, etc.); and a second linked to the external environment (i.e. arisen in later times as a result of atmospheric phenomena, air pollution, natural ageing, etc.). In this sense, the identification was made according to the principle of prudence, with the purpose of isolating the most characteristic or potentially 'dangerous problems', where avoiding redundant overlapping, to facilitate the recognition and understanding of the phenomena, and so to drive the project intervention, in any chosen direction by the client (fig. 6).

For the definition of the lexicon, reference was made when possible to the UNI 11182:2006 'Cultural Heritage - Natural and Artificial Stone - Description of the Alteration - Terminology and Definition', integrating it with entries the most closely related to the concerned material, following a progressive refinement of a specific vocabulary (Di Biase, Albani, 2009; Coppola, Buoso, 2015).

The decay mapping, greatly complicated by the lack of chromatic uniformity of the concrete, has been a long and laborious process, which demanded a careful study and a meticulous testing phase. Operated directly on realistic projections, it could enable both the identification of the contours and the areas affected by alterations and a clear reading of the substrate details.

This did not make it possible the use of the traditional (Normal 1/88) and/or opaque hatches but imposed the combined use of CAD software (for perimeters) and 2D graphics design software to produce high transparent screens to be superposed on cement colours and ensure a proper reading at several levels. To better highlight the discolorations phenomena, it was also decided to slightly warmer the colours tones, of course without adulterating the overall chromatic adherence of photo planes to the reality (fig. 7 and 8).

\section{CONCLUSIONS}

This work has raised various questions pertaining to the appropriateness and lifespan of past surface finish and maintenance actions, many of which not suitably conceived and carried out.

The analysis of the process of knowledge's results is now inducing a profound meditation on the modalities to follow for the effective conservation of this 'monument of contemporary world'.
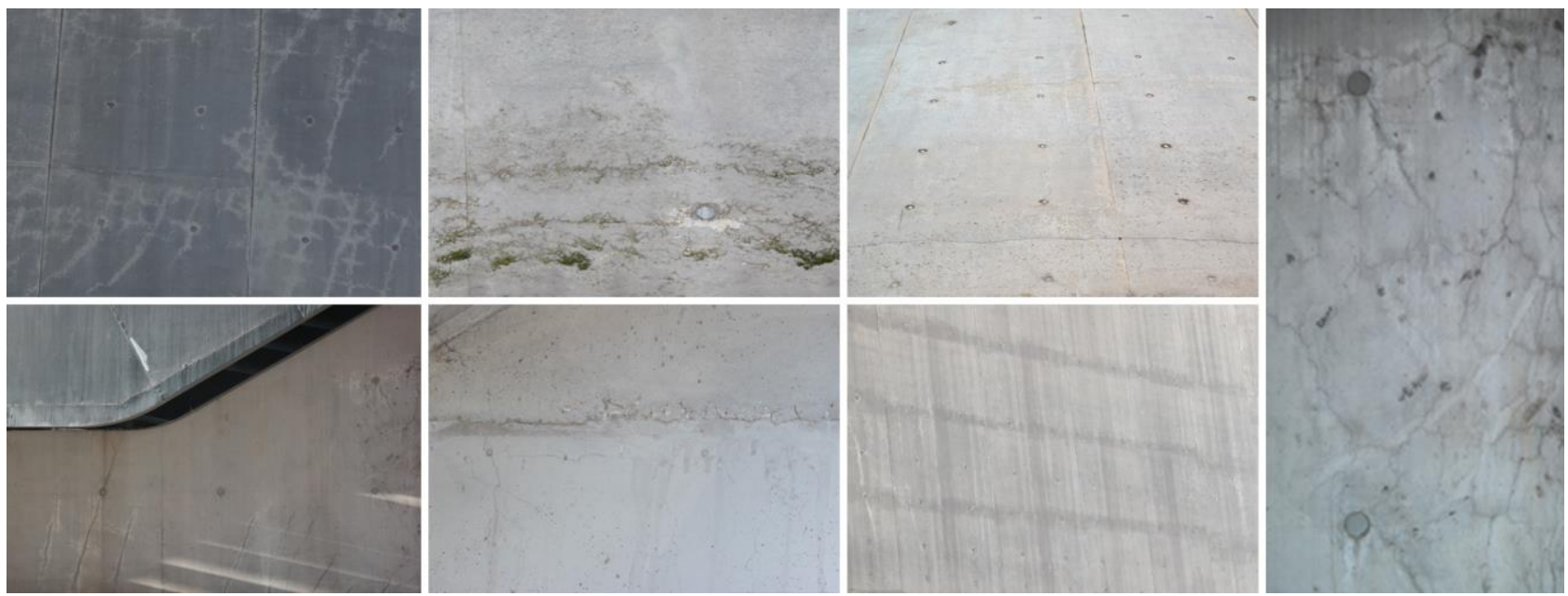

Figure 6. Some of pathologies and alterations affecting today the MAXXI 
The International Archives of the Photogrammetry, Remote Sensing and Spatial Information Sciences, Volume XLII-5/W1, 2017 GEOMATICS \& RESTORATION - Conservation of Cultural Heritage in the Digital Era, 22-24 May 2017, Florence, Italy

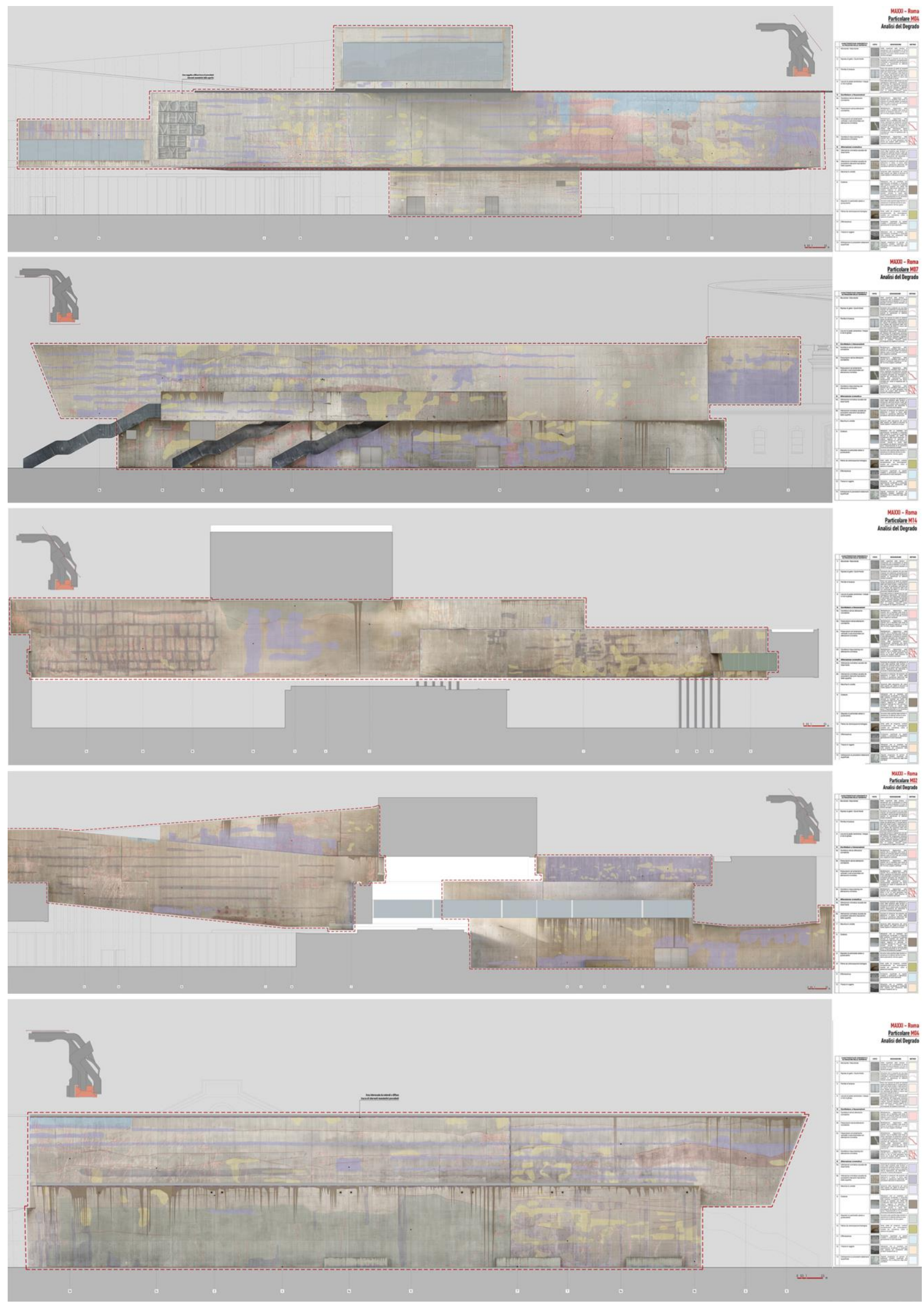

Figure 7. Decay mapping of eastern façades 


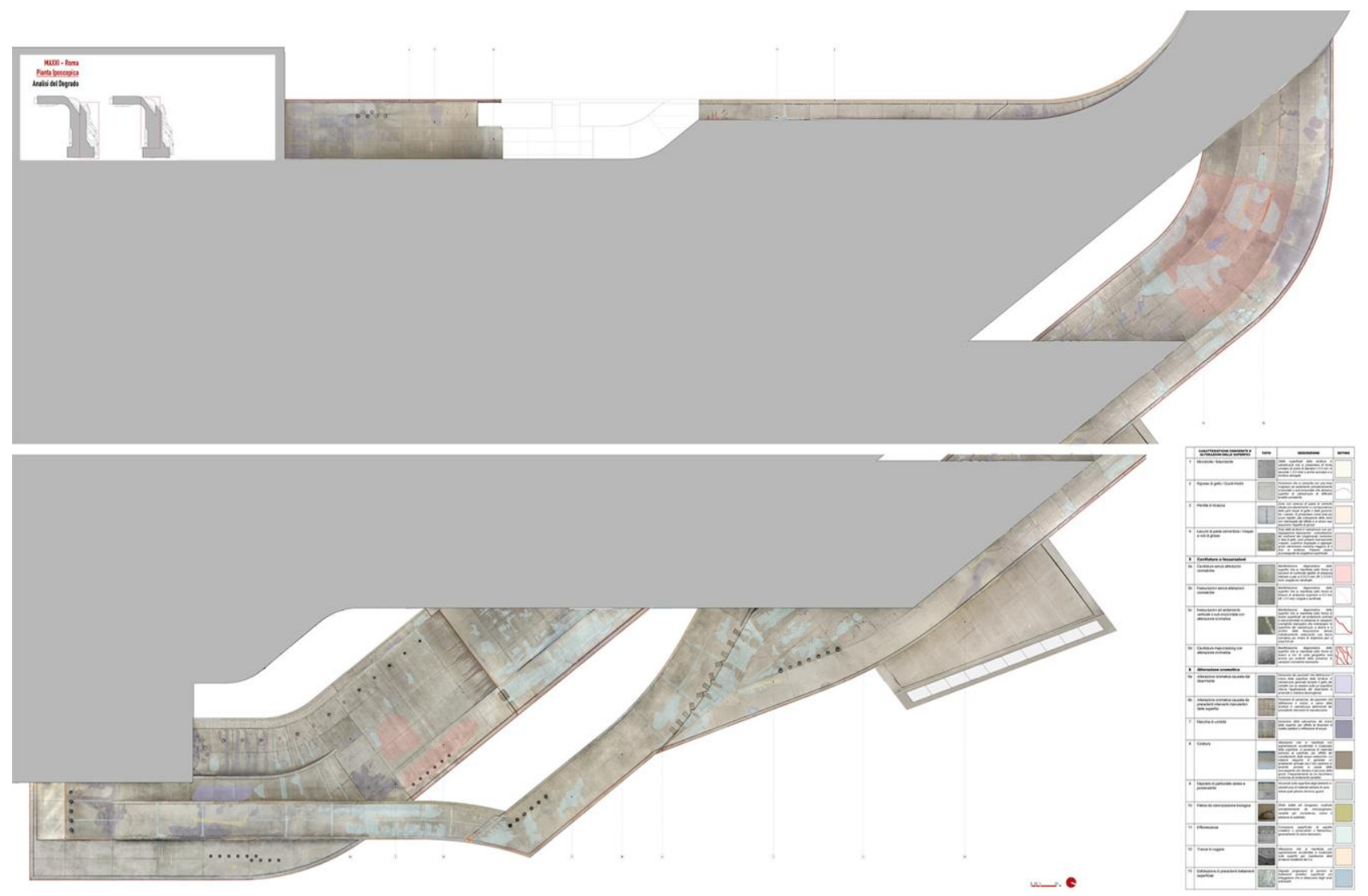

Figure 8. Decay mapping of hyposcopic view

A concept in some ways paradoxical because "if a building is to be restored, this already implies that the same is of an albeit recent past" (Dorfles, 2004). In fact, for the restoration of the modern and, even more, contemporary architecture, the temporal proximity to the construction - and then the lack of relationship with history that greatly influences the ancient building preservation strategies - has until now driven to operate essentially towards renovation work, to the detriment of the authenticity of the artifacts. Today, their historicizing has become the disciplinary and educational foundation for the development of the cultural motivations of the restorers of the future, for which the issue will further be pressing (Mariano, Giuliano, Marcelli, Petetta, 2017).

It, therefore, seems increasingly appropriate to establish methodological and procedural guidelines for the proper execution and implementation, not only of the conservation and rehabilitation interventions but also of the knowledge process and analyses for the understanding of this heritage, to which this work has intended to contribute.

\section{ACKNOWLEDGEMENTS}

The authors thank the Director of MAXXI Foundation, arch. Margherita Guccione, the arch. Mario Avagnina (Ministry of Superior Council of Public Works, designer of the maintenance programme) and the arch. Francesca Romana Liguori (Mibact Ministry of Cultural Heritage and Activities and Tourism, R.U.P. of the maintenance programme) for their support and precious suggestions.
While the authors shared objectives, methodology and conclusions of this paper, paragraphs 1 and 3 were written by A. Versaci, and 2 by A. Cardaci.

\section{REFERENCES}

Avagnina, M., Guccione, M., La Pergola, S., 2010. MAXXI materia grigia: il racconto della costruzione. Electa, Milano.

Cardaci, A., Versaci, A.,2012. Innovative methodologies of automatic color survey in the service of architectural restoration. In M. Rossi \& A. Siniscalco (ed.), Colore e Colorimetria: contributi multidisciplinari. Maggioli, Bologna, pp. 191-198.

Coppola L., Buoso A., 2015. Il restauro dell'architettura moderna in cemento armato. Alterazione e dissesto delle strutture in c.a. - diagnostica - interventi di manutenzione e adeguamento antisismico - materiali, tecniche e cantieristica. Hoepli, Milano.

Di Biase, C., Albani F., 2009. Alterations and decay in twentiethcentury architecture: A lexicon proposal. In F. M. Mazzolani (Ed.), Protection of Historical Buildings: PROHITECH 09: Proceedings of the International Conference on Protection of Historical Buildings, Rome, Italy, 21-24 June 2009. CRC Press, Boca Raton, pp. 519-524.

DiXit - RaiStoria, 2011. MAXXI. Museo Nazionale delle Arti del XXI Secolo, https://www.youtube.com/watch?v=asNYssAQR9I. 
Dorfles, F., 2004. Il restauro del Moderno rispetto all'Antico, Arte/Architettura/Ambiente, V (8), pp. 9-10.

Faccio, P., 2008. Il calcestruzzo storico: conservazione o ripristino?. In R. Ientile (ed.), Architetture in cemento armato. Orientamenti per la conservazione, Franco Angeli, Milano, pp. 198-204.

Fiorani, D., 2013. Il lato tecnico del restauro: opportunità, limiti e contenuti. In S. Musso (ed.), Nuove tecniche di restauro architettonico, Wolters Kluver Italia. Milano, pp. 33-60.

Ippolito, A., 2016. Handbook of Research on Emerging Technologies for Architectural and Archaeological Heritage. IGI Global, Hershey USA.

Mariano F., Giuliano, A. A., Marcelli F. \& Petetta, L., 2017. Restauro e conservazione dell'architettura del Novecento: l'esperienza dell'edilizia italiana tra gli anni Venti e Sessanta. Piani conoscitivi, strumenti operativi e sviluppi didattici. In D. Fiorani (Ed.), RICerca/REStauro, Quasar, Roma, pp. 448-457.

Purini, F., 1996. Una lezione sul disegno. Gangemi, Roma.

Varagnoli, C., 2002. Gli eccessi del restauro. Parametro, 239, pp. 68-69.

Vassallo, E., 2004. I segni del tempo. Restauro, Architettura, architetture. In S. Valtieri, Della Bellezza ne è piena la vista! Restauro e conservazione alle latitudini del mondo nell'era della globalizzazione, Atti del Convegno: Verso una filosofia pluralistica della conservazione per il XXI secolo, (Reggio Calabria 2003), Nuova Argos, Roma, pp. 158-175. 